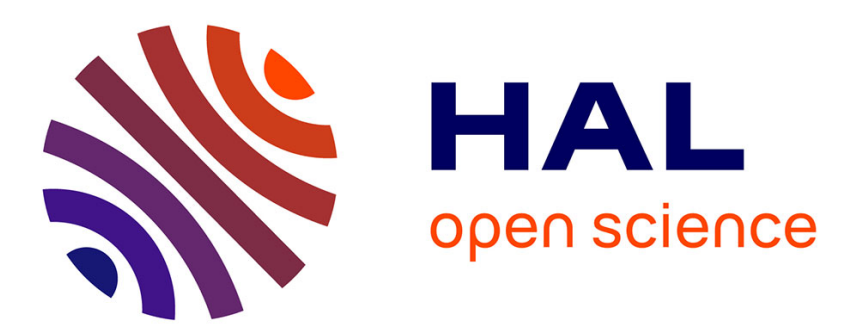

\title{
Identifying Price Reviews by Firms: An Econometric Approach
}

\author{
Mark Harris, Hervé Le Bihan, Patrick Sevestre
}

\section{To cite this version:}

Mark Harris, Hervé Le Bihan, Patrick Sevestre. Identifying Price Reviews by Firms: An Econometric Approach. Journal of Money, Credit and Banking, 2020, 52 (2-3), pp.293-322. 10.1111/jmcb.12675 . hal-02417497

\section{HAL Id: hal-02417497 https://hal-amu.archives-ouvertes.fr/hal-02417497}

Submitted on 11 Feb 2020

HAL is a multi-disciplinary open access archive for the deposit and dissemination of scientific research documents, whether they are published or not. The documents may come from teaching and research institutions in France or abroad, or from public or private research centers.
L'archive ouverte pluridisciplinaire HAL, est destinée au dépôt et à la diffusion de documents scientifiques de niveau recherche, publiés ou non, émanant des établissements d'enseignement et de recherche français ou étrangers, des laboratoires publics ou privés. 


\title{
Identifying Price Reviews by Firms: An Econometric Approach
}

\author{
Mark N. Harris ${ }^{\dagger}$ Hervé Le Bihan Patrick Sevestre $^{\S}$
}

\begin{abstract}
Price reviews are a potentially costly activity. A significant fraction of un-changed prices may stem from firms not reviewing prices, rather than from obstacles to changing prices per se, such as menu costs. In this paper, we disentangle these two causes of price stickiness by estimating an inflated ordered probit model on a panel of French manufacturing firms. The results point to a low frequency of price reviews, suggestive of the relevance of information costs as a determinant of the observed price stickiness. In view of the "inattentive producers" literature, pointing that the source of price rigidity matters, this is suggestive of a large real effect of monetary policy.
\end{abstract}

JEL codes: C23, C25, E31

Keywords: price stickiness, price reviews, price changes, inflated ordered probit model.

THE WIDELY DOCUMENTED EXTENT OF price stickiness (see, e.g., the survey by Klenow and Malin 2011) suggests that most firms do not systematically change their prices every time there is a change in their environment. Such a feature is corroborated by surveys, that are able to control for changes in wage and other input

The authors wish to acknowledge the financial support of the Australian Research Council and the Banque de France research foundation. The authors thank the editor, as well as Francesco Lippi and several referees for helpful comments and suggestions. They also thank participants to seminars at Banque de France, Paris-Est Créteil University, Aix-Marseille University, Monash University and to the 26th JMA conference (University of Dijon), the RCEF conference (University of Rimini), and the 16th International Conference on Panel Data (University of Amsterdam) for their comments on previous versions. The usual disclaimer applies. In particular, the views expressed herein are those of the authors and do not necessarily reflect those of the Banque de France.

$\uparrow$ School of Economics and Finance, Curtin University, Australia. e-mail: mark.harris@curtin.edu.

$\$$ Banque de France and Curtin University

$\S$ Universite' Aix Marseille. 
The widely documented extent of price stickiness (see, e.g., the survey by Klenow and Malin 2011) suggests that most $i\urcorner$ rms do not systematically change their prices every time there is a change in their environment. Such a feature is corroborated by surveys, that are able to control for changes in wage and other input prices changes for firms, as well as demand fluctuations (e.g., Blinder et al. 1998, Fabiani et al. 2006, Vermeulen et al. 2007, Loupias and Sevestre 2013). Another well-established fact is that most firms declare they review their prices only infrequently (Fabiani et al. 2006, Blinder et al. 1998). Reviewing their price, as we interpret it in the present paper-consistently with the relevant literature-is the process for firms of collecting and processing the necessary information to compute their optimal desired prices. ${ }^{1}$ Having computed this optimal desired price does not however necessarily imply that the firm will actually implement a price change, in particular if there is a cost to implementing such a price change. Thus, the absence of price review is only one of the possible causes of price stickiness.

This paper adds to the literature on price setting by providing a microeconometric assessment of the respective roles of firms' decisions to undertake price reviews and, possibly, a subsequent price change, for explaining the observed price stickiness at the firm level. To the best of our knowledge, no such previous assessment is available in the literature.

For that purpose, we estimate an inflated ordered probit (IOP) model (Harris and Zhao 2007, Brooks, Harris, and Spencer 2012) on firm-level data. The structure of this model is well suited to the modeling of the respective roles of price reviews and price changes in firms' price-setting decisions. Indeed, the absence of a price change, a commonly observed outcome at the firm level at a monthly or quarterly frequency, can be seen as the consequence of a two-step process: at any point in time, firms decide whether or not to undertake a price review: "no review" results in prices remaining unchanged (unless there is an "automatic" price-setting rule); while implementing a review can lead to prices being consequently either changed, or left unchanged. This sequencing is not observable by the applied economist: all she observes is the large proportion of no-change outcomes, without knowing how these were arrived at. The IOP model is typically appropriate in such a setup. In this respect, our paper also adds to the applied econometric literature by providing one more example of the capability of the IOP model to identify the respective determinants of the two phases of an observationally equivalent decision process.

We use a panel data set of French firms, setup by merging the monthly business survey ran by the Banque de France (BdF) with other data sources. A key feature of this data set is that a number of time-varying firm-level determinants of price changes are available. While a disadvantage of these data is that the information on price changes is only categorical, the use of an IOP model precisely handles this feature of the data.

Another advantage of our econometric approach is to circumvent restrictions that would be embedded in a standard Ordered Probit (OP) model approach, for example, and would be particularly harmful in a price review setup. In a standard OP model, finding that a variable affects the probability of a price change entails restrictions on the sign of its effect on the change in prices. For instance, if a positive coefficient is

1. Importantly, this definition of price review does not preclude that the firm may have access to some information about its environment between two price reviews. 
found in January, prices will therefore be predicted to be more likely to increase, and less likely to decrease then. By contrast, in the IOP model, an increased probability of price review, say, in January, can lead both the probability of a price increase and that of a price decrease to be larger in January.

Our main results relate to the estimated frequency of price reviews. We find that, on average in a given quarter, there is only about a $30 \%$ chance of a firm conducting a price review, and conditional on performing a price review, the probability of a price change is $75 \%$. Thus, a large fraction (about 90\%) of the occurrences of no-price-change observations actually corresponds to an absence of price reviews. Furthermore, price reviews obey mainly a time-dependent schedule, with, however, large or persistent shocks on input prices being found to trigger price reviews.

While matching our estimates with a particular structural model is beyond the scope of this paper, our results to point to the relevance of information frictions. This suggests that, in comparison with models generating the same amount of price stickiness based on "menu cost" type frictions, the real effect of monetary policy will be stronger and more persistent.

Related Literature. Our paper is related to several strands of the literature. One closely related set of works is the one focusing on explaining price changes based on firm-level data and using limited dependent variable econometric techniques: see Loupias and Sevestre (2013) (on which we build on, by using the same data set) and the references therein. One crucial improvement with respect to this literature is that we distinguish between price reviews and price changes, especially, in respect of explaining the large occurrence of no-change instances.

Our paper is also clearly connected to the empirical literature on price reviews. A huge subset of this literature is direct empirical evidence regarding firms' pricereviewing behavior obtained from specific surveys, such as the one run by Blinder et al. (1998) or those implemented in several Euro area countries in the context of the Inflation Persistence Network (Fabiani et al. 2006). According to these, firms review their prices infrequently. Indeed, Fabiani et al. (2006) show that only about $25 \%$ of firms in the Euro area review their prices at least monthly. At the other end of the spectrum, almost $60 \%$ of them review their prices at most three times per year. Loupias and Ricart (2006) provide similar results for France: among firms declaring they review their prices on a regular basis, that is, among time-dependent firms, $26 \%$ of firms review their prices monthly or weekly while $44 \%$ review them only once a year. We argue that our results, obtained from an econometric approach, are broadly consistent with these results.

Our paper is also connected to the empirical and theoretical literature concerned with the costs incurred by firms in processing information to determine their optimal price, as a rationalization for infrequent price reviews. A prominent empirical contribution by Zbaracki et al. (2004) has provided an evaluation of the managerial costs incurred by a U.S. manufacturing firm when revising its prices. On the theoretical side, important contributions are Sims (1998, 2003), Reis (2006), Woodford (2009), Alvarez, Lippi, and Paciello (2011). Our setup is acknowledgedly a flexible, reduced 
form, inspired by all these models. We argue that our specification is able to identify price reviews generated by these models, and we rely on these models to impose some identifying restrictions in our estimation. Furthermore, the theoretical literature (e.g., Mankiw and Reis 2002, Alvarez, Lippi, and Paciello 2016) has pointed that information frictions are likely to give rise to a substantial effect of monetary policy shocks, in particular as compared to standard sticky prices frictions. To the extent that our results point to a low frequency of price reviews, suggestive of the relevance of information costs, they support the assessment of a relatively large effect of monetary policy on output and inflation (all else equal).

The remaining of our paper is structured as follows. Section 1 details our econometric setup. Section 2 provides a connection with theoretical models of price review, both to rationalize our approach, and to motivate exclusion restrictions. Section 3 presents the data set and our empirical specification. Our estimation results are presented in Section 4. Section 5 concludes.

\section{PRICE REVIEWS AND PRICE CHANGES; DEVELOPING AN APPROPRI- ATE EMPIRICAL APPROACH}

In line with direct survey evidence of a two-step process, our model postulates that the pricing behavior of firms entails two decisions. The first one is whether firms undertake a price review in order to compute the desired optimal price. The second decision, conditional on a price review having been undertaken, is whether to increase or decrease prices or to leave them unchanged. Unfortunately, as typical in firm-level data with price data, our data set provides information about price changes implemented by firms, but does not provide any explicit information about whether firms conducted a price review or not. We are thus concerned with explaining an ordinal discrete dependent variable, where the no-change observations are assumed to be a result of a two-step process. Thus, we adopt the suggested approach as in Brooks, Harris, and Spencer (2012): the IOP model, with a structure as summarized in Figure 1.

Hence, any "no price change" event in the data in any given month can stem from either the firm not having implemented a price review, or from having decided to leave its price unchanged after having conducted a price review.

Formally, and in the first instance following the notation of Brooks, Harris, and Spencer (2012), the model "first" features an unobserved latent variable, $q_{i t}^{*}$ which represents the propensity of a firm $i$ to proceed to a price review at time $t^{2}$ This variable can be expressed as

$$
q_{i t}^{*}=\mathbf{x}_{i t}^{\prime} \beta+u_{i t},
$$

2. The subscript $i$ in our application will actually index a triplet of "firm-establishment-product" but most firms are observed for only one product. 


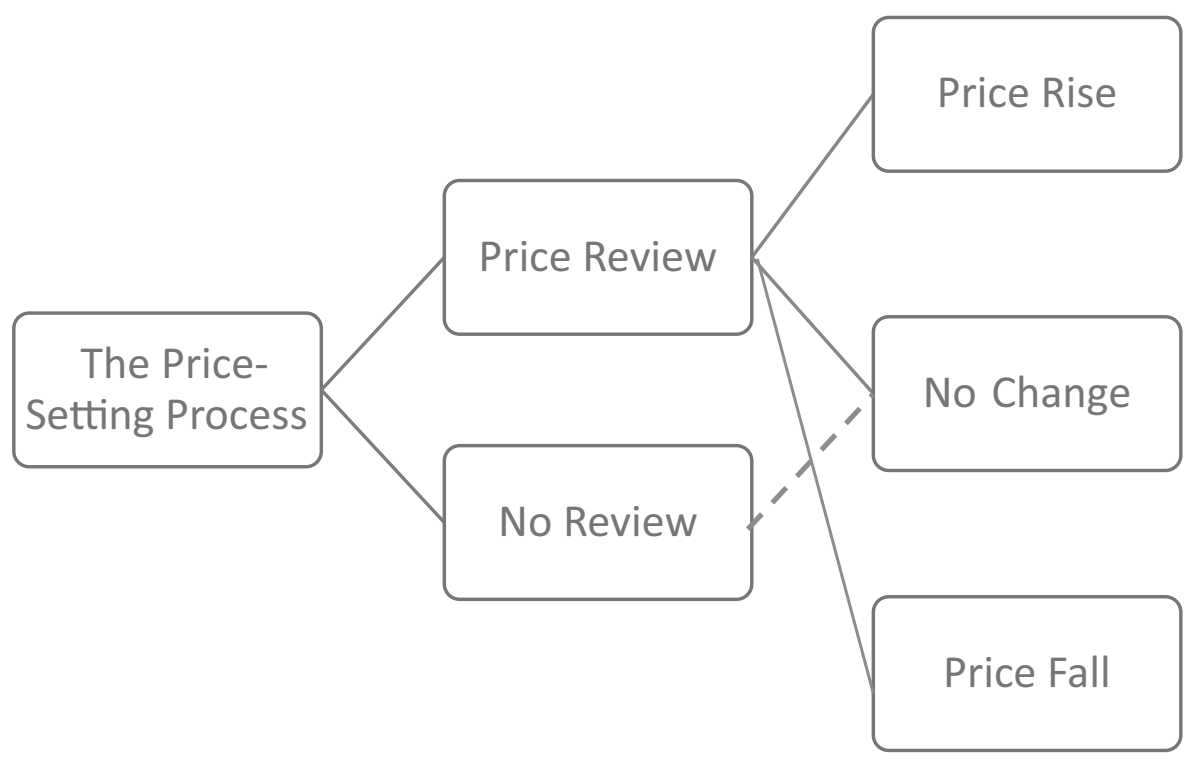

FIG. 1. Firms' Price Review and Price Change Process.

where $\mathbf{x}_{i t}$ is a vector of observed characteristics of the firm and its environment, and $u_{i t}$ follows a standard Gaussian distribution. Under the assumption of normality, the probability that the firm sees a justification for a price review is (Maddala 1983):

$$
\operatorname{Pr}\left(q_{i t}=1 \mid \mathbf{x}_{i t}\right)=\operatorname{Pr}\left(q_{i t}^{*}>0 \mid \mathbf{x}_{i t}\right)=\Phi\left(\mathbf{x}_{i t}^{\prime} \beta\right),
$$

and, for no price review:

$$
\operatorname{Pr}\left(q_{i t}=0 \mid \mathbf{x}_{i t}\right)=\operatorname{Pr}\left(q_{i t}^{*} \leq 0 \mid \mathbf{x}_{i t}\right)=1-\Phi\left(\mathbf{x}_{i t}^{\prime} \beta\right),
$$

where $\Phi(\cdot)$ represents the standard normal cumulative distribution function. Thus, as is standard in a zero-one choice setting, the index function must be positive before a review is seen as warranted.

This equation only represents a propensity for a price review: it says nothing about the existence of any desired price change nor about its direction. Moreover, even though a firm may have a strong propensity for a price review, current economic/market conditions may in fact dictate that no change in current prices is optimal. This suggests a two-regime scenario where the differing regimes split firms into a price review $\left(q_{i t}=1\right)$ or no price review $\left(q_{i t}=0\right)$ dimension. For those in regime $q_{i t}=0$, a no-change outcome is necessarily observed. For those in the alternative regime $q_{i t}=1$, the firm may (optimally) choose any of a price increase, decrease, or no change. As the available information about price changes in our context is qualitative (along the lines of decrease, increase, and no change), an 
appropriate modeling strategy is to use an OP model (Maddala 1983). For modeling the second stage of the price-setting process, without loss of generality, define observed outcomes as $y_{i t}=-1$ (a price reduction), $y_{i t}=0$ (no change), and $y_{i t}=1$ (increase). The outcome is driven by the dynamics of the underlying latent variable, that is, the desired price change $\Delta p_{i t}^{d}$ by the firm which will specified as

$$
\Delta p_{i t}^{d}=\mathbf{z}_{i t}^{\prime} \gamma+\varepsilon_{i t},
$$

where $\mathbf{z}_{i t}$ is a vector of observed characteristics with unknown weights $\gamma$ and $\varepsilon_{i t}$ a random disturbance term. The variance of $\varepsilon_{i t}$ is set to 1 , as it is not separately identified from the parameters in $\gamma$ (a standard feature in models in which the observed variable is categorical). ${ }^{3}$

In line with the so-called $(S, s)$ models of price rigidity (see, e.g., Sheshinski and Weiss (1977) for a seminal application to price setting, Cecchetti (1986) for a first empirical test, and Dixit (1993) for a neat textbook exposition), the price change process will be characterized by an "inaction range." A price increase will be triggered if the desired price change is larger than an upper threshold value $\mu_{2}$, while a price reduction will be observed if the desired price change is below a lower threshold $\mu_{1}$. The price will stay unchanged if the desired price change is in the range $\left[\mu_{1}, \mu_{2}\right]$. Note that the two thresholds are not imposed to be symmetric around zero, in line with predictions of theoretical $(S, s)$ models in the case of positive inflation.

Then under the usual assumption of normality, conditional on being in the "price review" regime, the associated probabilities of being in each state $j, j=-1,0,1$ are

$$
\operatorname{Pr}\left(y_{i t}\right)=\left\{\begin{array}{l}
\operatorname{Pr}\left(y_{i t}=-1 \mid \mathbf{z}_{i t}, q_{i t}=1\right)=\Phi\left(\mu_{1}-\mathbf{z}_{i t}^{\prime} \gamma\right) \\
\operatorname{Pr}\left(y_{i t}=0 \mid \mathbf{z}_{i t}, q_{i t}=1\right)=\Phi\left(\mu_{2}-\mathbf{z}_{i t}^{\prime} \gamma\right)-\Phi\left(\mu_{1}-\mathbf{z}_{i t}^{\prime} \gamma\right) \\
\operatorname{Pr}\left(y_{i t}=1 \mid \mathbf{z}_{i t}, q_{i t}=1\right)=1-\Phi\left(\mu_{2}-\mathbf{z}_{i t}^{\prime} \gamma\right) .
\end{array}\right.
$$

Here, notice that $\mu_{1}, \mu_{2}$, and any constant term in $\gamma$ cannot be separately identified. We thus do not include constant in the covariates, and refrain from interpreting the levels of the thresholds. ${ }^{4}$

Note that our model implies that producers do not change their prices between two price reviews. This assumption seems warranted, given the low inflation during the period under consideration, in particular in view of the theoretical results by Alvarez, Lippi and Paciello (2011) showing that "price plans" are not optimal under low inflation.

As we do not observe which regime a firm is in (i.e., we do not observe neither $q_{i t}^{*}$ nor $q_{i t}$ ), we cannot condition on regime in estimation. Let us first assume that $\varepsilon$ and $u$ identically and independently follow standard Gaussian distributions, then the

3. See Online Appendix I for a brief further discussion on identification restrictions.

4. This adds to the more familiar, and already mentioned absence of joint identifiability of the thresholds and the standard deviation of shocks. 
overall probability of observing either a price decrease, a price increase or no change, consists of two component parts such that

$\operatorname{Pr}\left(y_{i t}\right)=\left\{\begin{array}{l}\operatorname{Pr}\left(y_{i t}=-1 \mid \mathbf{z}_{i t}, \mathbf{x}_{i t}\right)=\Phi\left(\mathbf{x}_{i t}^{\prime} \beta\right) \Phi\left(\mu_{1}-\mathbf{z}_{i t}^{\prime} \gamma\right) \\ \operatorname{Pr}\left(y_{i t}=0 \mid \mathbf{z}_{i t}, \mathbf{x}_{i t}\right)=\left[1-\Phi\left(\mathbf{x}_{i t}^{\prime} \beta\right)\right]+\Phi\left(\mathbf{x}_{i t}^{\prime} \beta\right)\left[\Phi\left(\mu_{2}-\mathbf{z}_{i t}^{\prime} \gamma\right)-\Phi\left(\mu_{1}-\mathbf{z}_{i t}^{\prime} \gamma\right)\right] \\ \operatorname{Pr}\left(y_{i t}=1 \mid \mathbf{z}_{i t}, \mathbf{x}_{i t}\right)=\Phi\left(\mathbf{x}_{i t}^{\prime} \beta\right)\left[1-\Phi\left(\mu_{2}-\mathbf{z}_{i t}^{\prime} \gamma\right)\right] .\end{array}\right.$

So, to observe $y_{i t}=0$ (no change), we require either that $q_{i t}=0$ (absence of price review) or jointly that $q_{i t}=1$ (the firm undertakes a price review) and that $\mu_{1}<$ $\Delta p_{i t}^{d} \leq \mu_{2} .{ }^{5}$ In this way, observationally equivalent no-change observations can arise from two distinct sources: the price review equation combined with the price change equation, or the price review equation in isolation.

We stress that a significant advantage of this IOP approach over the standard OP one is that it entails less restrictions. In particular, in the price review/price change setup that we consider, it allows for the coexistence of state and time-dependent price-setting behaviors in a consistent way. For instance, models of price review tend to predict that price reviews will be time-dependent. Thus variables like the seasonal and duration dummies (see below) are likely to lead to "regular" price reviews and, possibly, price changes, without prejudice of the sign of the price change. By contrast, including these variables directly in a standard OP model would impose that a variable such as the seasonal dummy for the month of January should systematically increase desired prices (or alternatively, systematically decrease-depending on the sign of the coefficient), which need not be the case. Our specification allows that the probability of a price change is always larger in January, while allowing that the changes may be more decreases or increases depending on the covariates in the "price change" equation. In essence, in the IOP setup a variable can be included in both parts of the model, and potentially have different effects in each of them, whereas in an OP setup this is not possible. Moreover, in the latter a variable could indeed appear insignificant overall, whereas in actuality it is a strong driver of both true parts of the model, but with opposing effects.

Following Brooks, Harris, and Spencer (2012), we can also allow for the likely correlation between $\varepsilon$ and $u$, since they relate to the same firms (in the same time period), yielding probabilities of the form:

$$
\operatorname{Pr}\left(y_{i t}\right)=\left\{\begin{array}{l}
\operatorname{Pr}\left(y_{i t}=-1 \mid \mathbf{z}_{i t}, \mathbf{x}_{i t}\right)=\Phi_{2}\left(\mathbf{x}_{i t}^{\prime} \beta, \mu_{1}-\mathbf{z}_{i t}^{\prime} \gamma ;-\rho_{\varepsilon u}\right) \\
\operatorname{Pr}\left(y_{i t}=0 \mid \mathbf{z}_{i t}, \mathbf{x}_{i t}\right)=\left[1-\Phi\left(\mathbf{x}_{i t}^{\prime} \beta\right)\right]+\left\{\begin{array}{c}
\Phi_{2}\left(\mathbf{x}_{i t}^{\prime} \beta, \mu_{2}-\mathbf{z}_{i t}^{\prime} \gamma ;-\rho_{\varepsilon u}\right) \\
-\Phi_{2}\left(\mathbf{x}_{i t}^{\prime} \beta, \mu_{1}-\mathbf{z}_{i t}^{\prime} \gamma ;-\rho_{\varepsilon u}\right)
\end{array}\right. \\
\operatorname{Pr}\left(y_{i t}=1 \mid \mathbf{z}_{i t}, \mathbf{x}_{i t}\right)=\Phi_{2}\left(\mathbf{x}_{i t}^{\prime} \beta, \mathbf{z}_{i t}^{\prime} \gamma-\mu_{2} ; \rho_{\varepsilon u}\right),
\end{array}\right.
$$

5. See Online Appendix I. 
where $\Phi_{2}(a, b ; \rho)$ denotes the cumulative distribution function of the standardized bivariate normal distribution with correlation coefficient $\rho_{\varepsilon u}$ between the two univariate random elements.

Also the data at hand consist of repeated observations per firm. Using this we can straightforwardly condition on the likely unobserved heterogeneity of the firm, as is usual in the panel data literature (Wooldridge 2002). To this aim, we include random unobserved effects in both equations (1) and (4), such that they, respectively, become

$$
q_{i t}^{*}=\mathbf{x}_{i t}^{\prime} \beta+\alpha_{i}+u_{i t}
$$

and

$$
\Delta p_{i t}^{d}=\mathbf{z}_{i t}^{\prime} \gamma+e_{i}+\varepsilon_{i t}
$$

Although this quite significantly complicates estimation, the (log-)likelihood has, conditional on the individual effects, a tractable formulation and has been maximized using simulation techniques. ${ }^{6}$ Finally note that $\mathbf{z}_{i t}$ and $\mathbf{x}_{i t}$ are not requested to be disjoint, although imposing restrictions as we do, based on structural models underlying our set-up, improves identification. ${ }^{7}$

\section{RELATIONSHIPS WITH STRUCTURAL MODELS OF PRICE REVIEWS}

Our setup is essentially a reduced-form model, designed to disentangle the respective roles of price reviews and price changes in explaining price rigidity, and accommodating the characteristics of our data set such as the categorical nature of information on price changes. However, we argue that it can also be viewed as an empirical approximation to the theoretical models featuring infrequent price reviews such as those proposed by Reis (2006), Woodford (2009) and/or Alvarez, Lippi, and Paciello (2011). To illustrate this claim, we investigate to what extent our reducedform model can be related to theories of "inattentive producers" by focusing on the prominent model of Alvarez, Lippi, and Paciello (2011), which importantly allows for both observation and menu costs.

\subsection{Overview of a Benchmark Structural Model of Price Reviews}

Alvarez, Lippi, and Paciello (2011) assume that firms aim at "tracking" an optimal $(\log )$ price $p^{*}$ assumed to follow a random walk with drift, where the drift is the inflation rate and the innovations are idiosyncratic shocks with variance $\sigma^{2}$. The firm has to pay an observation $\operatorname{cost}(\theta)$ to observe the state, and a menu cost $(\psi)$ to adjust

6. See Online Appendix II.

7. See Online Appendix III for a discussion. 
its price. Both of these costs prevent the firm from continuously adjusting the price to its optimal value $p^{*}$.

Alvarez, Lippi, and Paciello (2011) first show that, in the case of low inflation, optimality dictates at most a single price adjustment between reviews, and that this should happen immediately after the review. This drives out the need to consider the possibility of "price plans." To the extent that we focus on a period of low inflation in France, this justifies the assumption in our model that price changes can only occur "immediately" following a price review. Under a set of standard assumptions, Alvarez, Lippi, and Paciello (2011) show that after a price review has occurred, the optimal time of the next review is

$T(\widetilde{p})=\tau$ for $\widetilde{p} \notin(-\bar{p}, \bar{p})$, that is, if the firm adjusts its price,

and $T(\widetilde{p})=\tau-\left(\frac{\tilde{p}}{\sigma}\right)^{2}+o\left(\left|\widetilde{p}^{3}\right|\right)$ otherwise,

where $\tilde{p}$ is the price gap, that is, the difference between the observed price and the target $p^{*}, \bar{p}$ is the threshold for changing prices, and $\tau$ is the maximum time elapsed between two reviews. Parameters $\bar{p}$ and $\tau$ are the outcome of the optimization process, and depend on the observation and menu costs, on the variance of shocks, as well as on the loss incurred if no adjustment occurs (a function inter alia of the degree of competition in the economy). According to their model, with low menu costs (and disregarding the possibility that large shocks may be partly observed), firms would adopt a purely time-dependent schedule for their price reviews. Alvarez, Lippi, and Paciello (2011) further show that the average frequency of price reviews is a decreasing function of both observation and menu costs, but increasing in the loss incurred if no adjustment occurs, as well as in the variance of shocks. As they emphasize, this model nests the two polar cases of pure state-dependence (menu costs only) and time-dependence (observation costs only).

Casually, a take away from this model is that the duration elapsed since last price review should be a primary determinant for the price review. Also, price reviews should not depend on contemporaneous variables. In practice however, Alvarez, Lippi, and Paciello (2011) state that it is likely that firms will have access to some free informations, especially if a large visible shock happens. This is what motivates us for including variables such as the incidence of "large shocks" among the determinants of price reviews (see Section 3.2).

\subsection{Simulation Experiments}

To illustrate the connection of the IOP econometric setup with structural models of price reviews, we run a simulation experiment, generating data using the Alvarez, Lippi, and Paciello (2011), henceforth ALP, model. Using each simulated data set, the IOP model described in Section 1 is estimated. Such an exercise will provide support to our econometric approach to the extent that this econometric setup is able to correctly recover the price review occurring in the theoretical model. 
TABLE 1

IOP Estimates Applied to Simulations of a Structural Model

\begin{tabular}{lllllll}
\hline & \multicolumn{7}{c}{ Panel A. Parameter sets } \\
\hline Case number & 1 & 2 & 3 & 4 & 5 & 6 \\
Value of $\theta$ (observation costs) & 0.005 & 0.03 & 0.005 & 0.03 & 0.005 & 0.03 \\
Value of $\psi$ (menu costs) & 0.005 & 0.005 & 0.015 & 0.015 & 0.03 & 0.03 \\
\hline
\end{tabular}

Panel B. Results with benchmark specification (1)

(B.1) Actual and inferred probabilities of price review (pct)

\begin{tabular}{|c|c|c|c|c|c|c|}
\hline Theoretical & 45.3 & 28.7 & 46.1 & 24.3 & 47.8 & 24.4 \\
\hline Estimated & 56.5 & 25.1 & 43.1 & 23.0 & 41.9 & 23.4 \\
\hline Prob. price change & 24.6 & 20.5 & 16.8 & 14.1 & 13.9 & 11.2 \\
\hline
\end{tabular}

(B.2) Significance of covariates of the price review equation

\begin{tabular}{lllllll}
\hline Time since last review & 95.1 & 100.0 & 99.9 & 99.7 & 99.9 & 99.8 \\
$|\tilde{p}|$ at last review & 93.0 & 100.0 & 66.3 & 99.8 & 92.2 & 99.4 \\
\hline
\end{tabular}

(B.3) Significance of covariates of the price change equation

\begin{tabular}{|c|c|c|c|c|c|c|}
\hline $\begin{array}{l}\text { Time since last review } \\
\tilde{p} \text { at last review } \\
\text { Time since last change } \\
\text { Current } \tilde{p}\end{array}$ & $\begin{array}{r}4.9 \\
8.1 \\
4.4 \\
100.0\end{array}$ & $\begin{array}{r}3.5 \\
4.2 \\
5.4 \\
95.4\end{array}$ & $\begin{array}{r}5.2 \\
7.9 \\
4.9 \\
100.0\end{array}$ & $\begin{array}{r}3.2 \\
5.1 \\
4.7 \\
98.2\end{array}$ & $\begin{array}{r}5.3 \\
8.5 \\
4.2 \\
100.0\end{array}$ & $\begin{array}{r}3.4 \\
4.4 \\
5.4 \\
99.8\end{array}$ \\
\hline \multicolumn{7}{|c|}{$\begin{array}{l}\text { Panel C. Results without } \tilde{p} \text { at last review in specification (1) } \\
\text { (C.1) Actual and inferred probabilities of price review (pct) }\end{array}$} \\
\hline $\begin{array}{l}\text { Theoretical } \\
\text { Estimated } \\
\text { Prob. price change }\end{array}$ & $\begin{array}{l}45.3 \\
38.0 \\
24.6\end{array}$ & $\begin{array}{l}28.7 \\
24.2 \\
20.5\end{array}$ & $\begin{array}{l}46.1 \\
39.1 \\
16.8\end{array}$ & $\begin{array}{l}24.3 \\
20.2 \\
14.1\end{array}$ & $\begin{array}{l}47.8 \\
56.3 \\
13.9\end{array}$ & $\begin{array}{l}24.4 \\
19.7 \\
11.2\end{array}$ \\
\hline
\end{tabular}

(C.2) Significance of covariates of the price review equation

\begin{tabular}{lrrrrrr}
\hline Time since last review & 100.0 & 100.0 & 100.0 & 100.0 & 100.0 & 100.0 \\
\hline \multicolumn{7}{c}{ (C.3) Significance of covariates of the price change equation } \\
\hline Time since last review & 3.0 & 1.0 & 3.0 & 4.0 & 1.0 & 2.0 \\
Time since last change & 7.0 & 2.0 & 6.0 & 3.0 & 3.0 & 5.0 \\
Current $\tilde{p}$ & 100.0 & 95.0 & 100.0 & 98.0 & 100.0 & 100 \\
\hline
\end{tabular}

Notes: The table displays the outcome of a Monte Carlo experiment involving $S=1,000$ simulations for each of the parameter sets listed in the first row. In each simulation, the model of Alvarez, Lippi, and Paciello (2011) is simulated with a sample size of 1,000 observations. Using each simulated data set the IOP (Inflated Ordered Probit) model described in the text is estimated. Numbers in the second and third panel of the table report the percentage of times in which each variable is found significant using a $5 \%$ level test.

Concretely, for a range of model parameters, the ALP model is simulated with a sample size of 1,000 periods. ${ }^{8}$ Parameter values that we consider in the datagenerating process are inspired by the numerical parameter values considered in ALP, and are reported in the second and third rows of Panel A in Table 1. For each of the parameter sets, we run a Monte Carlo experiment involving $S=1,000$ simulations

8. The model by Alvarez, Lippi, and Paciello (2011) is in continuous time, we simulate a discrete-time random walk approximation. 
of a sample and $S$ estimations of the IOP model. Results are reported in the bottom panels of Table 1 .

Based on the theoretical model, in our IOP model, the elapsed time since last review, and the absolute value of $\tilde{p}$ at last review are used as covariates in the price review equation. Similarly, for the price change equation we use time since last review, time since last price change, the current value of $\tilde{p}$, and the value of $\tilde{p}$ at last change. Panel B.1 reports the average theoretical and estimated probabilities of price review: while the former are known in our controlled experimental setup, they are treated as unobserved in the econometric procedure. Numbers in Panels B.2 and B.3 report the percentage of times in which each variable is found significant using a 5\% test. Several results stand consistently across parameter sets. First, the econometric model is able to recover relatively precisely the (unknown/unobserved to the econometrician) probability of price reviews, which varied substantially across the various parameter sets. In all but one case, the model underestimates somewhat the true probability of price review. Second (from Panel B.2), as consistent with the theoretical model, the duration variable "time since last review" is a significant predictor of the probability of a review, as is the (absolute) value of the price gap as last observed. Third, "time dependent" variables such as time since last change and time since last review are not significant factors triggering price changes (typically they are significant only in $4 \%$ and $8 \%$ of the cases, consistent with no predictive power given the selected level of the test). This is again consistent with the theoretical model. By contrast, the current value of the price gap, $\tilde{p}$, a "state-dependent" covariate is always significant in triggering price changes.

To investigate the robustness of the above findings, we have carried out additional Monte Carlo exercises, which we now briefly present and discuss. First, we have performed the exercise without assuming that the price gap at last review is observed by the econometrician. This case on the one hand matches a relevant feature of our empirical setup. It is to be stressed on the other hand that in this case we take for granted that the estimated model is misspecified. ${ }^{9}$ Results are presented in Panel C of Table 1. As expected, the ability of the model to correctly identify price reviews is lower, but the procedures still does a quite good job at doing so. For instance, in the median case for menu cost values $(\psi=0.015)$ and "low" menu cost $(\theta=0.005)$ the estimated probability of price review is $39 \%$ against $43 \%$ in the baseline specification case, and an actual probability of $46 \%$. In the "high" menu cost case $(\theta=0.03)$, the estimated probability of price review is now $20 \%$ against $23 \%$ in the baseline specification case, and an actual probability of $24 \%$.

Second we have investigated a larger set of parameters, that is, more "extreme" parameter cases in terms of the ratio of menu cost to observation cost, and in particular outside the range of values considered by ALP. Results are reported in Table 2. The bottom line is that the model still appears to perform fairly well in terms of recovering

9. We overall consider the baseline results, that is, what happens if the price gap at last review is included as a regressor to be a useful benchmark. Indeed, the price gap observed at last price review is a covariate consistent with the ALP model. The baseline set of results allows to assess to what extent our reduced-form specification-the IOP-is an appropriate approximation of the structural model. 
TABLE 2

Additional Monte Carlo Simulations of a Structural Model: Extended Parameter Sets

\begin{tabular}{|c|c|c|c|c|c|c|c|}
\hline \multicolumn{8}{|c|}{ Panel A. Parameter sets } \\
\hline \multirow{3}{*}{\multicolumn{2}{|c|}{$\begin{array}{l}\text { Case number } \\
\text { Value of } \theta \text { (observation costs) } \\
\text { Value of } \psi \text { (menu costs) }\end{array}$}} & \multirow{3}{*}{$\begin{array}{c}1 \\
0.003 \\
0.005\end{array}$} & \multirow{3}{*}{$\begin{array}{l}2 \\
0.03 \\
0.005\end{array}$} & \multirow{3}{*}{$\begin{array}{c}3 \\
0.06 \\
0.005\end{array}$} & \multirow{3}{*}{$\begin{array}{c}4 \\
0.003 \\
0.045\end{array}$} & \multirow{3}{*}{$\begin{array}{c}5 \\
0.03 \\
0.045\end{array}$} & \multirow{3}{*}{$\begin{array}{c}6 \\
0.06 \\
0.045\end{array}$} \\
\hline & & & & & & & \\
\hline & & & & & & & \\
\hline \multicolumn{8}{|c|}{$\begin{array}{l}\text { Panel B. Actual and inferred probabilities of price review (pct) } \\
\text { Baseline } \sigma\end{array}$} \\
\hline Theoretical & 63.4 & & & 20.9 & 73.6 & 24.6 & 18.6 \\
\hline Estimated & 58.2 & & & 17.6 & 59.1 & 21.7 & 27.5 \\
\hline Prob price change & 29.6 & & & 16.3 & 0.7 & 9.8 & 9.0 \\
\hline \multicolumn{8}{|c|}{ Small $\sigma$} \\
\hline Theoretical & 18.7 & & & 5.8 & 47.5 & 6.4 & 5.1 \\
\hline Estimated & 15.1 & & & 4.9 & 47.2 & 7.4 & 6.1 \\
\hline Proba price change & 7.2 & & & 4.1 & 2.1 & 2.3 & 2.2 \\
\hline
\end{tabular}

NotES: The table displays the outcome of a Monte Carlo experiment involving $S=1,000$ simulation for each of the parameter sets listed in the first row. In each simulation, the model of Alvarez-Lippi-Paciello is simulated with a sample size of 1,000 observations. Using each simulated data set the IOP (Inflated Ordered Probit) model described in the text is estimated. In the "Baseline $\sigma$ " case, $\sigma=0.15$ the benchmark value in ALP. In the "Small $\sigma$ " case, $\sigma$ is set to 0.03 .

the probability of a price review. One main case in which the model performance happens to worsen significantly is whenever the cost of a price review is low (implying a high theoretical frequency of price review), while at the same time the frequency of price change is low (reflecting a large value of the menu cost). ${ }^{10}$

Finally, our third additional exercise investigates the implications of our assumption of homogeneity of parameters for all firms in our sample. This is a potential concern, as the literature dedicated to estimating menu costs models has emphasized that menu costs are likely to differ across sectors, and it is likely that the frequency of price reviews also varies across sectors. Such a feature may induce aggregation biases in setups like ours. Arguably two elements in our setup are likely to mitigate this concern, namely, that (i) all our data are from the manufacturing industry sector and (ii) we include industry-level fixed effects at the two-digit levels. ${ }^{11}$ However, it is informative investigating the consequences of neglected heterogeneity. We draw on Nakamura and Steinsson (2010) and Gautier and Le Bihan (2018) to calibrate the degree of heterogeneity. Based on evidence in these papers, we assess that having a two-sector model captures to a large extent the degree of heterogeneity in the economy; and that a three-to-one ratio is an empirically reasonable ratio between sectors with large menu costs and sectors with small menu costs. So we simulate in turn three data generating processes (DGPs): (i) two subsamples differing according to the value of the menu cost $\left(\psi^{1}=0.005\right.$ and $\left.\psi^{2}=0.015\right)$; (ii) two subsamples differing

10. The case with the largest discrepancy in Table 2 has an estimated probability of price review of $59.0 \%$ vs. an actual one of $73.6 \%$.

11. Examples of two-digit levels categories are "Manufacture of motor vehicle," and "Manufacture of pharmaceutical products." 
TABLE 3

Additional Monte Carlo Simulations of the Structural Model: Case with Heterogeneity

\begin{tabular}{|c|c|c|c|}
\hline \multicolumn{4}{|c|}{ Panel A. Parameter sets } \\
\hline Case number & 1 & 2 & 3 \\
\hline Value of $\theta_{1}$ (observation costs) & 0.030 & 0.030 & 0.030 \\
\hline Value of $\theta_{2}$ (observation costs) & 0.030 & 0.005 & 0.005 \\
\hline Value of $\psi_{1}$ (menu costs) & 0.015 & 0.015 & 0.015 \\
\hline Value of $\psi_{2}$ (menu costs) & 0.005 & 0.015 & 0.005 \\
\hline \multicolumn{4}{|c|}{ Panel B. Actual and inferred probabilities of price review (pct) } \\
\hline Theoretical & 26.4 & 35.1 & 36.1 \\
\hline Estimated & 24.0 & 35.5 & 34.1 \\
\hline \multicolumn{4}{|c|}{ Panel C. Significance of covariates of the price review equation } \\
\hline Time since last review & 100.0 & 99.6 & $\begin{array}{l}99.8 \\
085\end{array}$ \\
\hline$|\tilde{p}|$ at last review & 100.0 & 97.3 & 98.5 \\
\hline
\end{tabular}

Panel D. Significance of covariates of the price change equation

\begin{tabular}{lrrr}
\hline Time since last review & 4.1 & 4.1 & 2.9 \\
$\tilde{p}$ at last review & 5.0 & 7.8 & 6.1 \\
Time since last change & 5.2 & 6.2 & 4.8 \\
Current $\tilde{p}$ & 99.3 & 100 & 100.0
\end{tabular}

Notes: The table displays the outcome of a Monte Carlo experiment involving $S=1,000$ simulation for each of the parameter sets listed in the first row. In each simulation, the model of Alvarez-Lippi-Paciello is simulated with a sample size of 1,000 observations. Using each simulated data set the IOP (Inflated Ordered Probit) model described in the text is estimated. Numbers in Panels C and D of the table report the percentage of times in which each variable is found significant using a $5 \%$ level test.

according to the value of the observation cost $\left(\theta^{1}=0.005\right.$ and $\left.\theta^{2}=0.03\right)$; and (iii) four subsamples, mixing heterogeneity in menu costs and observation costs. In each case, the IOP model is estimated assuming homogeneity in parameters and pooling the various samples. Then we compare the frequency of price reviews recovered by the misspecified model with the actual one. ${ }^{12}$ Results are reported in Table 3 . The main broad result of this exercise is that, even under heterogeneity that is not controlled for, our empirical model still captures relatively well the aggregate frequency of price reviews. For instance, in case (i) the theoretical frequency of price review is $26.5 \%$ and the one recovered by our procedure under the homogeneity assumption is $24.0 \%$. In case (ii), theoretical and estimated frequencies are $35.1 \%$ versus $35.4 \%$. In case (iii), frequencies are $36.0 \%$ versus $36.4 \%$.

\subsection{Implications for Empirical Specification and Identification Strategy}

We conclude this section by discussing the implications of our simulation exercises for the empirical specification, and by summarizing our identification strategy. A first

12. Importantly, in the simulated data we do identify price reviews. So, even if the data-generating process cannot be captured by a single parameter set (so that a one-sector model is in fact misspecified), we are still able to compute a meaningful average probability of price review, by averaging frequencies over the two subsamples. 
takeaway is that the above exercises provide important support to the ability of our model to identify the frequency of price reviews based on the observed patterns of price changes. This takeaway comes with some caveats. Admittedly, our empirical setup does not fully match the ideal one of the Monte Carlo simulations. Indeed, we are not sure about which precise model generates the data, and we do not want to stick to one single model of information stickiness. Another challenge is that we do not observe $p^{\star}$ but proxies for it, and that our empirical implementation will rely on time elapsed since last price change (rather than since last price review, as reviews are not observed in our data).

Our simulation exercises, as well as the theoretical literature on price reviews, are informative on what variable $x_{i t}$ to include in the equation for probability of a price review, and which $z_{i t}$ in that for price change. Concerning, first, the probability of a price review, we expect from the structural model of ALP that it should not depend on any contemporaneous variable, except from the elapsed duration since the previous price change or price review. Consistently, in the equation for price review, we will mainly exclude contemporaneous variables. Drawing on Woodford (2009), we will however allow that some information is freely available to the firm. We will assume that large shocks can be observed freely, as it presumably requires little monitoring to observe a large shock (say a financial crisis materializing in sharp decrease in demand, or an oil price shock), by contrast with the fine tuning of computing the optimal price. Also, one take away from the ALP model is that competition should incentivize firms to review prices more often. We will use a proxy for competition that is available in the cross-section dimension of our data.

In the equation for the size of a price change, we do not observe the price gap, a main determinant of price changes suggested by theory as well as our Monte Carlo simulations. However, as typically the change in price aims at setting the price gap to zero, and as optimal price is generally obtained as a markup of prices over marginal costs, the cumulated changes in costs since the last price change will be used as a relevant proxy for the price gap. As evidenced by the simulations above, the duration since last price change, or price review, is not expected to significantly influence the probability of a price change, once it is conditioned on a price review and on other covariates. We will thus exclude elapsed durations from the price change equation.

Overall, the above model-based restrictions underlie our identification strategy, that is, how our model is assumed to be able to identify price reviews, which are not observed instances. Eliciting this strategy largely amounts to characterizing in which instances we can conjecture that there was a price review, when at the same time the price is observed not to change. Based on the specification choices spelled out above, the model will infer a price review associated with no price change whenever (i) no price change is observed, while at the same time: (ii) a long time is elapsed since the last price change, and (iii) the cumulated change in the determinants for price changes are close to zero. Concretely, infrequent price reviews will be assessed to be an important factor behind price rigidity if, for a given level of the cumulated change in price changes determinants, price changes are more frequent when the last price change occurred a long time ago. The contribution of infrequent price reviews 
will also be assessed as important if, for a given elapsed duration, there are price changes observed even when the cumulated change in input prices is small. The first case is suggestive of large observation costs, while the second one of low menu costs.

\section{THE DATA AND EMPIRICAL SPECIFICATION}

This section first provides a general overview of the data used and of the main characteristics of the resulting estimation sample, then presents our empirical specification. As the data sources are identical to those used in Loupias and Sevestre (2013), the interested reader is referred to this paper for more detailed information.

\subsection{Data Sets}

The estimation sample is obtained by merging four data sets: three firm-level and one industry-level data set. The former are, respectively: (i) the series of the BdF monthly business surveys; (ii) the IPN French survey, an ad hoc survey about pricesetting practices in the French manufacturing industry (conducted by the BdF in 2004); and (iii) the ACEMO data set from the French Ministry of Labour containing information about firms wages and employment. The industry-level data set consists of the set of monthly producer price indices computed by INSEE (the French national statistical institute), at the two-digit NACE level. Merging these separate data sets yields a panel data set with extensive information regarding firm pricing behavior, wages, and other prices, as well as information regarding the degree of competition firms face.

The core of our database relies on the monthly BdF manufacturing industry business surveys over the period January 1996-December 2009. Each observation in this database refers to a specific product, defined at the four-digit NACE level, produced in a given plant/establishment of a firm. For simplicity, observational unit will be referred to as a "firm" hereafter. ${ }^{13}$ About 300 different product groups are considered. On the whole, the set of business surveys contains about 658,000 observations, corresponding to about 10,250 different firm products. The average number of units interviewed is about 4,000 per month. Firms are asked questions, among other things, regarding the evolution of product prices, intermediate input prices, production, orders received, and employment, both during the month in question and also during the previous 12 months. Here, we rely on the following primary variables from these data: variation in the price of the firm's product; variation in the price of intermediate inputs; and variation in firm output levels. For each of these variables, the information available is qualitative, and we distinguish three outcomes: decrease; no change; and increase. ${ }^{14}$

13. An observational unit is a triplet "firm-establishment-product," but the majority of surveyed entities consists of firms with only one establishment and one product. A few large firms with several establishments in our data may be surveyed more than once in a given month and some (large) establishments may report for more than one product as well.

14. Seven outcomes are actually distinguished in the initial database, from large/medium/small decrease to small/medium/large increase through "no change." Given the small number of both "large" and 
The "Competition" variable was obtained from the IPN French survey (see Loupias and Ricart 2006).

As the BdF business survey includes no information regarding labor costs, a relevant element in firms' total costs, we augment our base data set with data from an alternative source, the ACEMO survey. ${ }^{15}$ We use a weighted average of employee category-level of base wage to construct an indicator of the firm's wage cost. ${ }^{16}$ As the ACEMO survey is quarterly while the BdF business surveys is a monthly survey, we convert the ACEMO to the monthly frequency by assuming as Loupias and Sevestre (2013), that wage changes occur during the first month of each quarter. Two facts justify this assumption. First, survey evidence such as Fabiani et al. (2006) point that there is, in France as in other countries, a clustering of wage changes in January. Second, until 2009, the minimum wage in France was by law adjusted in July each year (i.e., the first month of the third quarter) following an indexation rule linking minimum wage to the consumer price index (CPI) inflation and to the increase in blue-collar workers average wage. Merging the ACEMO and BdF business surveys with the producer price indices (PPI hereafter) yields the same estimation sample as that used in Loupias and Sevestre (2013), with an extension in the time dimension as the estimation period covered here is 1999-2009, versus 1999-2005 in their paper. Further matching this sample with the IPN French survey yields a final sample for estimation of some 25,113 observations regarding the pricing decisions of 692 firms and their environment. Producer price indices at the industry level have been collected from the INSEE website using the two-digit NACE decomposition of the manufacturing industry. This variable allows us to measure sectoral shocks that may affect all firms in a given industry.

We define a set of dummy variables characterizing whether a firm at a given date experiences a "large shock" on, respectively, intermediate input prices, wage cost, firm production level, and industry-level producer price index. ${ }^{17} \mathrm{~L}$ Shock(iip) and $L$ Shock(prod) are dummy variables representing the occurrence of a change in intermediate input price and production declared by firms as either "moderate" or "large," the two largest possible outcomes in the BdF business survey. Moderate or large decreases in intermediate input prices represent about $1 \%$ of the observations, while moderate or large increases in production represent about $5 \%$ of observations. Also, a wage change is defined as a large shock $(\operatorname{LShock}($ wage $)=1)$, if it is, in absolute value, larger than $3 \%$, that is, about 1.5 times the average annual inflation rate. $L$ Shock $(p p i)$ is a dummy variable representing the occurrence of a significant

"moderate" increases and decreases, and in order to make these changes measured on the same basis as those of wages obtained from the ACEMO survey, we collapse these outcomes to three outcomes. However, the detailed, seven-outcome scales were used in order to define "large shocks" on input costs and production (see Section 3.2).

15. See Le Bihan, Montornès, and Heckel (2012) for a thorough presentation of the ACEMO survey.

16. As the base wage represents nearly $80 \%$ of gross earnings (Le Bihan, Montornès, and Heckel 2012), we argue the indicator is reliable.

17. The subscripts "iip,"“wage," "prod," and "ppi" will be similarly used in the mnemonics for defining other variables. 
TABLE 4

Characteristics of Changes in Firms' Environment

\begin{tabular}{|c|c|c|c|c|}
\hline & $\begin{array}{c}\text { Probability } \\
\text { of occurrence }\end{array}$ & increases & $\begin{array}{l}\text { of which } \\
\text { large shocks }\end{array}$ & persistent shocks \\
\hline Change in product price & $21.0 \%$ & $11.9 \%$ & - & - \\
\hline Change in input prices & $28.7 \%$ & $19.7 \%$ & $7.4 \%$ & $16.5 \%$ \\
\hline Change in wages & $20.3 \%$ & $18.4 \%$ & $1.4 \%$ & $20.3 \%$ \\
\hline Change in production & $66.1 \%$ & $35.8 \%$ & $35.3 \%$ & $37.7 \%$ \\
\hline
\end{tabular}

Notes: The data set contains 25,113 observations about 692 firms and the sample period is October 1998-December 2009. SouRCE: Banque de France business surveys merged with the ACEMO survey.

\section{TABLE 5}

Probability of Price Changes

\begin{tabular}{lccc}
\hline \hline & \multicolumn{3}{c}{ Probability of a price change conditional on: } \\
\cline { 2 - 4 } & a change in & a large shock on & a persistent shock on \\
\hline input prices & $40.3 \%$ & $51.0 \%$ & $42.9 \%$ \\
wages & $24.2 \%$ & $21.7 \%$ & $24.2 \%$ \\
production & $22.1 \%$ & $22.1 \%$ & $22.6 \%$ \\
\hline
\end{tabular}

NOTES: The data set contains 25,113 observations about 692 firms and the sample period is October 1998-December 2009. SourCE: Banque de France business surveys merged with the ACEMO survey.

producer price change, at the industry level, with an absolute magnitude over the ninth decile of the producer price index variations.

We also define a set of dummy variables (P_Shock(iip), P_Shock(wage), $P_{-}$Shock(prod), and $\left.P_{-} \operatorname{Shock}(p p i)\right)$ to capture lasting or "persistent" shocks. We consider for this purpose changes in the same direction, that were repeatedly observed in consecutive periods $t-2, t-1$, and $t$. For example, P_Shock $($ iip $)=1$ in April 2003 if input prices increased (decreased) at that date but also already increased (decreased) in February and March 2003.

\subsection{The Estimation Sample: Basic Facts}

The average frequency of price changes in the sample is $21.0 \%$ per month, which is close to the figures provided in previous studies about producer prices in France and the Euro area (Vermeulen et al. 2007, Loupias and Sevestre 2013). As Table 4 shows, changes in production costs and changes in the production level are significantly more frequent than price changes. Conditional on a change in costs or production level, the probability that the firm changes its price is significantly lower than 1 . This points to some rigidity in producer prices. This statistic however, is not informative on the intensity of price review. 
Table 5 provides more detailed characteristics of producer price changes. We highlight three facts. First, only a limited fraction of observed changes in costs or in the firm production level do induce a price change (column 1).

Second, the likelihood of a price change is significantly larger when firms declare they are facing a change in intermediate input prices, than when they face wage or production changes. This likelihood moreover significantly increases when the change in intermediate input prices is declared to be large, which does not seem to be the case for changes in wages or production (column 2). Third, a price change is also more likely when there is a persistent shock to input prices (column 3).

Another feature of our data is that price changes are subject to some seasonality as well as to a significant duration dependence. ${ }^{18}$ Indeed, firms change their prices significantly more in January than during other months of the year. By contrast, August and December are the two months with the least frequent price changes.

In line with a recurrent empirical finding across studies, our data feature a decreasing pattern of the hazard function of price changes. As has been put forward by a relatively large literature, this pattern is likely to result from the aggregation of heterogeneous sectors, each with possibly constant or even increasing hazard functions (see, e.g., Fougère, Le Bihan, and Sevestre 2007 or Alvarez, Burriel, and Hernando 2005). The hazard function also displays a significant spike at 12 months, indicating some duration dependence: many firms change their prices on an annual basis.

\subsection{Drivers of Price Reviews and Price Changes}

We now describe in detail our empirical specification, that is, the variables $x_{i t}$ appearing in the price review equations, and those $z_{i t}$ appearing in the price change equation. Following the logic outlined in Section 2.3, we implement some exclusion restrictions that are guided by the theoretical models, and are helpful for empirical identification.

The specification of the process for price reviews is summarized in equation (10).

$$
\begin{aligned}
& q_{i t}^{\star}=\sum \beta_{1}^{(k)} \text { Dummy }(\text { Duration }=k)+\sum \beta_{2}^{(j)} \operatorname{Dummies}(\text { Month }=j) \\
& +\beta_{3} \text { Competition }_{i}+\beta_{4} \operatorname{Var}(\text { iip })_{i}+\beta_{5} \operatorname{Var}(\text { wage })_{i}+\beta_{6} \operatorname{Var}(\text { prod })_{i}+\beta_{7} \operatorname{Var}(\text { ppi })_{i} \\
& +\beta_{8} L \_ \text {Shock }(\text { iip })_{i t}+\beta_{9} L_{-} \operatorname{Shock}(\text { wage })_{i t}+\beta_{10} L_{-} \operatorname{Shock}(\text { prod })_{i t}+\beta_{11} L_{-} \operatorname{Shock}(\text { ppi })_{i t} \\
& +\beta_{12} P \text { Shock }(\text { iip })_{i t}+\beta_{13} P_{-} \text {Shock }(\text { wage })_{i t}+\beta_{14} P \text { Shock }(\text { prod })_{i t}+\beta_{15} P \_ \text {Shock }(\text { ppi })_{i t} \\
& + \text { Dummies(industry, year, euro, VATchange })+u_{i t} \text {. }
\end{aligned}
$$

18. See Figures A.1 and A.2 in Online Appendix for the probability of price changes across months, and across elapsed durations of price spells. 
The equation for price reviews thus include three sets of covariates. The first set contains variables associated with a "time-dependent" price-setting behavior: first, a set of dummies Duration $_{1}$, Duration $_{2}, \ldots$, Duration $_{14}$, Duration $_{15-24}$, accounting for the duration (in months) elapsed since the last price change. Their coefficients correspond to a piecewise hazard function, allowing for possible duration dependence (the omitted, "reference" dummy being the one for an elapsed duration larger than 2 years). Second, a series of monthly dummies accounting for seasonality (the dummy variable for December, taken as the reference month, is omitted).

A second group of variables, following the results in ALP, aims at allowing the intensity of price reviews to vary across firms according to the variability of the firm's environment and to the loss incurred in the absence of adjustment (the parameters $\sigma^{2}$ and $B$ in Alvarez, Lippi, and Paciello 2011). The latter is approached through a variable measuring the degree of competition firms face: Competition is a dummy variable which equals 1 when the firm faces more than four competitors and 0 otherwise. ${ }^{19}$ In line with the ALP model, stronger competition induces a larger cost for the firm of not adjusting, and thus more frequent reviews. The variability of the firm's environment $\left(\sigma^{2}\right)$ is proxied by the variables: $\operatorname{Var}($ iip $), \operatorname{Var}($ wage), and $\operatorname{Var}(\operatorname{prod})$-which represent the firm-specific frequencies of intermediate input price, wage, and production changes as proxies to their volatilities; and $\operatorname{Var}(p p i)$, which represents the volatility of the sector-specific producer price index, as measured by its standard error.

In addition, following the argument of Woodford (2009), we also assume that, whenever a "sufficiently large" shock occurs, firms undertake a price review. We use the "large shock" variables defined above: L_Shock(iip), L_Shock(prod), $L_{-} S h o c k(w a g e), L_{-} S h o c k(p p i)$. Relatedly, the set of dummy variables for persistent shocks (P_Shock(iip), P_Shock(wage), P_Shock(prod) and $\left.P_{-} S h o c k(p p i)\right)$ are also included in the review equation. The logic is that, in case firms report their input price to have increased (or decreased) for 3 months in a row, they would more likely review their prices soon, as they realize that the price gap is inflating. This can account for the "shortening" of the time interval between reviews induced by the price gap magnitude.

We finally include a set of control variables $V A T_{1}$, a dummy variable for the decrease in the Value Added Tax rate that occurred in April 2000; while $V A T_{2}$ is a similar one for the months of January to April 2000 (to account for possible anticipated reactions to the preannounced change in the VAT rate). EURO $O_{1}$ is a dummy variable taking the value 1 for observations dated January 2002 (Euro cash changeover) and 0 otherwise; and $E U R O_{2}$ is an indicator variable for observations dated between July 2001 and June 2002 (that is, a 1-year window around the Euro cash changeover). Finally, a set of sector dummies and year dummies are included to capture the variability of the environment at the industry level or features of the pricesetting behaviors which are specific to a given industry $\left(\operatorname{Ind}_{10}, \ldots, \operatorname{Ind}_{32}, \operatorname{Ind}_{33}\right)$,

19. Four is the median of the declared number of competitors by firms on their output market. 
defined at the NACE two-digit level, or which are common to all firms during a given year $(1999, \ldots, 2008,2009)$.

The disturbance of the price review equation $\left(u_{i t}\right)$, has an error components structure, such that we account for the (product/firm-level) unobserved heterogeneity component of the price review decision.

The equation for price changes relies on proxies for the price gap, since typically a price change will aim at resetting the price gap to zero. Price changes are a function of current and lagged cumulated changes in, respectively, the price of intermediate inputs, wages, the production level of the firm, and the sectoral price index, the latter corresponding to a common shock at the industry level. The specification is summarized in equation (11).

$$
\begin{aligned}
\Delta p_{i t}^{d}= & \gamma_{1} \Delta \text { iip }_{i t}+\tilde{\gamma}_{1} \Delta \operatorname{iip}_{i, t-1, R}+\gamma_{2} \Delta \text { Wage }_{i t}+\tilde{\gamma}_{2} \Delta \text { Wage }_{i, t-1, R} \\
& +\gamma_{3} \Delta \operatorname{Prod}_{i t}+\tilde{\gamma}_{3} \Delta \operatorname{Prod}_{i, t-1, R}+\gamma_{4} \Delta p p i_{i t}+\tilde{\gamma}_{4} \Delta p p i_{i, t-1, R} \\
& + \text { Dummies(industry, year, euro, VATchange })+\varepsilon_{i t},
\end{aligned}
$$

where $\Delta i i p_{i t}$ is the current variation (increase, decrease, no change) of the firm intermediate input prices; $\Delta i i_{i, t-1, R}$ is the remaining input price change since the start of the spell, whenever the spell lasts longer than 1 month; $\Delta W a g e_{i t}$ is the current variation of the firm wage cost (increase, decrease, no change); $\Delta W a g e_{i, t-1, R}$ is as above; $\Delta \operatorname{Prod}_{i t}$, the current variation (increase, decrease, no change) of the firm production level; $\Delta \operatorname{Prod}_{i, t-1, R}$, as above; and $\Delta p p i_{i t}$, the current variation of the industry-level producer price index (increase, decrease, no change); and $\Delta p p i_{i, t-1, R}$ is as above. To make the covariate for wages (initially a quantitative variable) comparable with covariates like intermediate input prices and production, and get comparable estimates, we have transformed it in terms of increase, decrease, or no change. ${ }^{20}$

The other variables affecting price changes correspond to "special events" such as the VAT change in 2000 and the Euro cash changeover (both defined above); as well as sector and year dummies, that also appear in the price review equation. The disturbance $\varepsilon_{i t}$ in the price change equation is assumed to have an error component structure, as with that in the price review equation. That is, we allow for individuallevel unobserved heterogeneity both in the price review and price change equations. Moreover, as these relate to the same unit of observation, we also allow these two unobserved heterogeneity terms to be correlated with each other. Finally, a possible concern is that some of the explanatory variables might be endogenous to the price change decision of the firm. To handle this, we rely on approaches set out by Rivers and Vuong (1988) and Wooldridge (2005). ${ }^{21}$

20. Note that the cumulated increases are cumulated dummies, thus imperfectly measuring cumulated changes in the explanatory variables.

21. See Online Appendix IV for details. 
TABLE 6

AnCILlary Parameter Estimates

\begin{tabular}{lcc}
\hline \hline Parameter & Coefficient & Standard error \\
\hline$\mu_{1}$ & 0.067 & $(1.94)^{* *}$ \\
$\mu_{2}$ (price change) & 0.977 & $(0.07)^{* *}$ \\
$\sigma_{e}^{2}$ (price review) & 0.479 & $(0.06)^{* *}$ \\
$\sigma_{\alpha}^{2}$ (pr* & $(0.02)^{* *}$ \\
$\sigma_{\alpha e}$ & 0.196 & $(0.02)^{* *}$ \\
$\rho$ & -0.084 & $(0.06)$ \\
Log-likelihood & -0.056 & \\
\hline
\end{tabular}

Notes: $* *$ and $*$ denote significant at $5 \%$ and $10 \%$ size, respectively. Robust standard errors are in parentheses.

\section{ESTIMATION RESULTS}

This section presents estimation results based on our full model, with correlated equations and full, correlated, random effects. We have, however, estimated several variants of the proposed IOP model, allowing the price review and price change equations to be either independent or correlated; and including or not a full set of (correlated) random effects in both equations: the basic structural coefficients are essentially unchanged across model specifications. ${ }^{22}$

As Table 6 indicates, the auxiliary parameters $\left(\sigma_{e}^{2}\right.$, variance of price change unobserved effects; $\sigma_{\alpha}^{2}$, variance of price review unobserved effects; and $\sigma_{\alpha e}$, covariance of these effects) are individually strongly significant, and all jointly significant. One exception is $\rho$ (the correlation in equation (7)) not found to be significant, and very small in absolute value.

\subsection{The Estimated Frequencies of Price Reviews and Price Changes}

We start by providing a general assessment of the ability of the model to fit the data, of the estimated average probability for firms to implement price reviews, and of the contribution of (the absence of) price reviews to the observed price stickiness.

First of all, the coefficients of the identifying variables in the review equation, as well as in the price change equation are in most cases significant (parameter estimates are reported in Tables A.2 and A.3 in the Online Appendix). This is suggestive that the model is properly identified. Regarding the fit of the model, the average predicted probabilities are very close to the observed sample proportions of price increases and decreases (a plot of the observed sample proportions of price decreases, no-change and price increases along with the corresponding average model predicted probabilities is available in Figure A.3). This is an-obviously partial and rough-indication that the model fits the data well.

22. Results for the other models are available from the authors. 
More crucially, the model allows to decompose the total probability of a "no price change" outcome into that arising from the estimated absence of price review, and that stemming from the firms decision to leave prices unchanged after having implemented a review. The average estimated probability of implementing a price review during a given month is, over the whole sample, equal to 0.28 (this figure is computed by evaluating the probabilistic expressions given by equation (2) and then averaging over the sample). As a consequence, the bulk of no-price-change observations are estimated to arise from firms not reviewing their prices. Indeed, the total no-price-change probability is 0.79 , so a fraction of around $90 \%$ of these unchanged-price change outcomes can be attributed to the absence of price reviews (as $(1-0.28) / 0.79=0.91)$. It is worth noting that we experimented with a range of specifications, and these overall summary results appeared very robust across these. For example, in the simpler model with no correlations or unobserved effects, the total probability of no change (at 0.79 ) and of no review (at 0.72 ) was identical to those from our baseline model. Using an extended sample available when discarding the Competition variable from the model, ${ }^{23}$ the predicted overall no-change probability is 0.80 , of which 0.71 comes from the no review component of the model.

In order to benchmark and assess the relevance of these findings, we compare them with the frequencies of price reviews self-reported by firms, as obtained from the IPN French survey (Loupias and Ricart 2006). As this survey was implemented during the Winter 2003-04, we computed the estimated average probability of a price review (obtained from our preferred model and specification) for the period July 2003-June 2004, to make it more comparable with the results from the survey and to neutralize seasonal effects. Based on our model estimates, the average estimated probability of a price review over this particular period was 0.28 (while that of a price change was 0.21 ). This is a bit lower but compares to the average probability of a price review stemming from the IPN French survey which is equal to $0.38 .{ }^{24}$ We argue the latter is an upper bound, as in the survey it is obtained from the answers of firms, conditional on declaring they adopt a time-dependent schedule for their price reviews.

By contrast, our estimate accounts for all firms, be they time-dependent or statedependent. Although the IPN French survey does not provide direct evidence of the frequency of price reviews for state-dependent firms, we have indications that these firms review their prices less frequently than time-dependent firms. Indeed, state-dependent firms are most likely to change their price when a large shock occurs in their environment (see Loupias and Ricart 2004). While such large shocks are quite likely to also induce a price review, such "large shock" events do not

23. Ignoring this variable allows us estimating the model without having to restrict to the subsample covered by the IPN French survey, from which this Competition variable is obtained. The resulting sample is much larger as it contains 73,329 observations but the estimation results remain essentially unchanged.

24. We compute this figure based on the numbers provided in table 1 of Loupias and Ricart (2006), as the average probability of implementing a price review based on the following correspondence between the frequency of price reviews and the probability of reviewing prices within a given month. Declaring reviewing prices monthly or weekly is associated with a probability 1 to review prices in a given month; reviewing prices quarterly is associated with a probability $1 / 3$; twice a year with a probability $1 / 6$; once a year with $1 / 12$, and less than once a year with a probability $1 / 24$. 
TABLE 7

Price Review Equation Estimates (Partial Effects on Probability of Review)

\begin{tabular}{|c|c|c|c|c|c|}
\hline \multicolumn{3}{|c|}{ Time-dependent factors } & \multicolumn{3}{|c|}{ State-dependent factors } \\
\hline Duration $_{1}$ & 0.246 & $(0.03)^{* *}$ & L_Shock(iip) & 0.218 & $(0.02)^{* * *}$ \\
\hline Duration $_{2}$ & 0.081 & $(0.03)^{* *}$ & L_Shock(wage) & 0.199 & $(0.21)$ \\
\hline Duration $_{6}$ & 0.004 & $(0.04)$ & L_Shock(prod) & 0.019 & $(0.01)^{*}$ \\
\hline Duration $_{12}$ & 0.191 & $(0.04)^{* *}$ & L_Shock $(p p i)$ & 0.053 & $(0.01)^{* *}$ \\
\hline January & 0.270 & $(0.04)^{* *}$ & $P \_$Shock (iip) & 0.138 & $(0.01)^{* * *}$ \\
\hline February & 0.116 & $(0.02)^{* *}$ & P_Shock(wage) & -0.041 & $(0.05)$ \\
\hline March & 0.120 & $(0.02)^{* *}$ & P_Shock(prod) & 0.017 & $(0.01)^{*}$ \\
\hline April & 0.108 & $(0.03)^{* *}$ & P_Shock (ppi) & 0.006 & $(0.01)$ \\
\hline May & 0.046 & $(0.02)^{* *}$ & Var_II P & 0.266 & $(0.04)^{* * *}$ \\
\hline June & 0.074 & $(0.02)^{* *}$ & Var_Wage & 0.015 & $(0.08)$ \\
\hline July & 0.085 & $(0.03)^{* *}$ & Var_PROD & -0.026 & $(0.04)$ \\
\hline August & -0.007 & $(0.03)$ & Var_PPI & 1.843 & $(0.70)^{* * *}$ \\
\hline September & 0.082 & $(0.02)^{* *}$ & Competition & 0.024 & $(0.01)^{*}$ \\
\hline October & 0.080 & $(0.02)^{* *}$ & & & \\
\hline November & 0.051 & $(0.02)^{* *}$ & & & \\
\hline December & Reference & - & & & \\
\hline
\end{tabular}

Notes: ** and * denote significant at $5 \%$ and $10 \%$ size, respectively. Robust standard errors in parentheses. IIP, WAG, PROD, and PPI stand, respectively, for Intermediate Input Price, Wages, Production, and Producer Price Index. Full variable definitions are given in the text.

appear very frequent, according to the frequency of price changes declared by statedependent firms (see Loupias and Ricart 2004). On average, state-dependent firms thus seem to review their prices less frequently. Given the quite significant proportion of firms adopting a state-dependent behavior, the IPN French survey estimate (0.38) of the probability of a price review, based on the only answers of timedependent firms, is arguably an upper bound for the overall probability of a price review.

According to the IPN French survey, the absence of price reviews "accounts for" $73 \%$ of unchanged prices $(=(1-0.38) / 0.85)$. This figure is broadly comparable to that obtained from our estimated model when considering the subperiod July 2003June 2004: $0.91=(1-0.28) / 0.79$. The quite strong contribution of infrequent price reviews to the observed price rigidity appears to be a common feature of our estimated model and of the IPN French survey. ${ }^{25}$

We now comment in turn of the role of the determinants of price reviews and price changes.

\subsection{Explaining Price Reviews}

As the estimated model coefficients are difficult to interpret, we focus on a selection of partial effects in both the price review equation, and then the price change equation. Table 7 presents some marginal effects for a selection of both state-dependent and

25. Figures A.4 and A.5 in the online appendix provide "flow charts" that summarize these estimates from both the IPN French survey and our model estimates. 


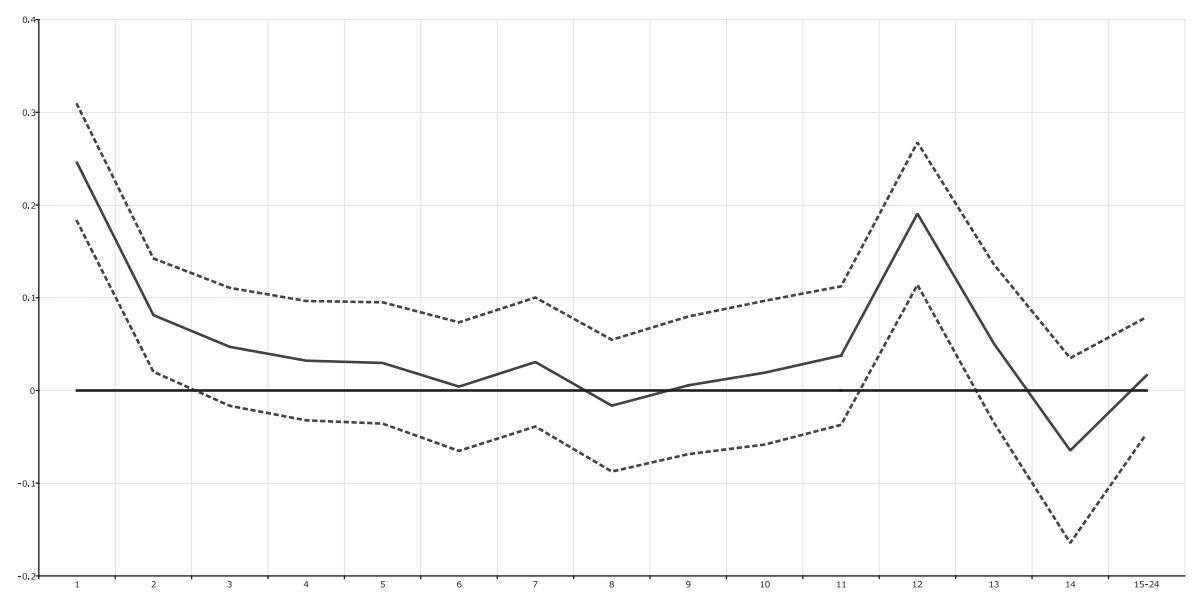

FIG. 2. The Estimated Conditional Hazard Function for Price Reviews.

NOTE: Omitted category is "Duration $>25$ months."

time-dependent determinants of price reviews. ${ }^{26}$ We consider essentially three groups of factors that may explain price reviews: (i) seasonal and duration dependence factors, typical time-dependent factors; (ii) the volatility of firms' environment and the degree of market competition and; (iii) large shocks affecting firms' environment.

Results in Table 7 point to the importance of seasonality and duration dependence as key determinants of price reviews. First, many price reviews appear to be implemented in January. In January, firms are 27pp more likely to proceed to a price review than in December (the reference month). February to April, and, to a lesser extent, September and October, also appear to be periods with a significant increase in price reviews. Moreover, these estimation results point to a significant duration dependence in firms' price-setting behavior. The dummy variable for elapsed duration $=12$ months is very significant (unlike most other dummies except the one for 1 month and to a smaller extent for 2 months). Thus, a time-dependent "yearly" effect appears to trigger price reviews. The conditional hazard function, that is, here the marginal effects of the elapsed duration dummies, is plotted in Figure 2. As our specification already controls for seasonal dummies, the observed duration dependence of price changes is not a consequence of the only "January effect." Many firms review their prices on a yearly basis, but not necessarily in January each year. The importance of such time-dependent factors is in line with the evidence from the numerous surveys conducted in the Euro area about firms pricing behaviors (see Loupias and Ricart 2006 or Fabiani et al. 2006) which point to the existence of a significant fraction of firms that adopt a time-dependent calendar for price reviews.

26. The full coefficients estimates (with the exception of the control function variables) are nevertheless provided in Tables A.2 and A.3; the full set of marginal effects are available from the authors on request. 
The decreasing pattern of the hazard function over the durations up to 11 months does not appear significant, suggesting our specification controls relatively well for heterogeneity in price-setting practices. Still the significant spike at duration 1 month suggest there may be a subset of firms facing a quite volatile environment (or low observation costs) and thus proceeding to very frequent price reviews.

Table 7 indicates that the variability of shocks on input prices increases the frequency of price reviews; so does the intensity of competition. These results are consistent with the predictions of the model proposed by Alvarez, Lippi, and Paciello (2011) where the maximum period length between two reviews is a decreasing function of the variability of shocks, and of the loss incurred when failing to adjust. ${ }^{27}$ This shows that indeed, firms for which inattention is more costly pay more attention to their prices.

Large and/or persistent variations in intermediate input prices appear to be other important factors triggering price reviews. Large shocks on production and on the producer price index also have a significant positive impact on price reviews but to a lesser extent. These findings are consistent with the predictions of the models of Woodford (2009) and Alvarez, Lippi, and Paciello (2011). They are also in line with the observation in Apel, Friberg, and Hallsten (2005) and validate the view by Golosov and Lucas (2007), Dhyne et al. (2011), and Mackowiak and Wiederholt (2009) that idiosyncratic shocks play an important role in firms' price-setting behavior. Even firms which usually have a time-dependent timing of their price reviews may switch to a state-dependent behavior when they face a significant shock on input prices. Somewhat surprisingly, we find little statistical evidence of any effect (large or persistent shock, nor volatility) of wages on the probability of price reviews. We conjectured this could be a consequence of the time-dependent schedule of wage increases: wages are often increased on the 1st of January each year and/or on the 1st of July which was the date at which the minimum wage was usually increased during the sample period. The impact of wage increases was, however, also nonsignificant when we removed the time-dependent monthly dummies present in our model. Two plausible explanations for this outcome are the measurement error regarding the exact date of wage changes, and the small share of labor cost in manufacturing industry with respect to other inputs, making it difficult to identify the effect of shocks to labor cost.

Our results also confirm previous findings that the VAT changes and the Euro cash changeover do not seem to have had any significant impact on manufacturing firms' pricing behavior (with the exception of the $E U R O_{1}$ dummy, which significantly reduced review probabilities).

\subsection{Explaining Price Changes}

We turn next to the determinants of price changes, conditional on the firms implementing a price review.

27. See also Konieczny and Rumler (2006) for another theoretical model explaining why this may be optimal for firms to adopt such a strategy. 
TABLE 8

Price Change Equation Estimates (Partial Effects on Conditional and Marginal Probabilities)

\begin{tabular}{|c|c|c|c|c|c|c|}
\hline & \multicolumn{3}{|c|}{ Conditional on review } & \multicolumn{3}{|c|}{ Marginal } \\
\hline & Decrease & No change & Increase & Decrease & No change & Increase \\
\hline \multirow[t]{2}{*}{$\Delta I I P_{i t}$} & -0.233 & -0.071 & 0.304 & -0.055 & -0.017 & 0.072 \\
\hline & $(0.09)^{* *}$ & $(0.03)^{* *}$ & $(0.11)^{* *}$ & $(0.02)^{* *}$ & $(0.01)^{* * *}$ & $(0.03)^{* *}$ \\
\hline \multirow{2}{*}{$\Delta I I P_{i t-1, R}$} & -0.102 & -0.031 & 0.133 & -0.024 & -0.007 & 0.031 \\
\hline & $(0.02)^{* *}$ & $(0.01)^{* *}$ & $(0.02)^{* *}$ & $(0.00)^{* *}$ & $(0.00)^{* *}$ & $(0.00)^{* *}$ \\
\hline \multirow[t]{2}{*}{$\Delta$ Wage $_{i t}$} & -0.033 & -0.010 & 0.043 & -0.008 & -0.002 & 0.010 \\
\hline & $(0.03)$ & $(0.03)$ & $(0.04)$ & $(0.01)$ & $(0.01)$ & $(0.01)$ \\
\hline \multirow[t]{2}{*}{$\Delta$ Wage $_{i t-1, R}$} & 0.007 & 0.002 & -0.009 & 0.002 & 0.000 & -0.002 \\
\hline & $(0.02)$ & $(0.00)$ & $(0.02)$ & $(0.00)$ & $(0.00)$ & $(0.00)$ \\
\hline \multirow[t]{2}{*}{$\triangle P R O D_{i t}$} & -0.115 & -0.035 & 0.149 & -0.027 & -0.008 & 0.035 \\
\hline & $(0.05)^{* *}$ & $(0.03)$ & $(0.06)^{* *}$ & $(0.01)^{* *}$ & $(0.01)$ & $(0.01)^{* *}$ \\
\hline \multirow{2}{*}{$\triangle P R O D_{i t-1, R}$} & -0.038 & -0.011 & 0.049 & -0.009 & -0.003 & 0.012 \\
\hline & $(0.01)^{* *}$ & $(0.01)^{*}$ & $(0.01)^{* *}$ & $(0.00)^{* *}$ & $(0.00)^{* *}$ & $(0.00)^{* *}$ \\
\hline \multirow[t]{2}{*}{$\triangle P P I_{i t}$} & -0.052 & -0.016 & 0.068 & -0.012 & -0.004 & 0.016 \\
\hline & $(0.02)^{* * *}$ & $(0.04)$ & $(0.02)^{* * *}$ & $(0.01)^{* *}$ & $(0.01)$ & $(0.01)^{* *}$ \\
\hline \multirow[t]{2}{*}{$\triangle P P I_{i t-1, R}$} & -0.026 & -0.008 & 0.034 & -0.006 & -0.002 & 0.008 \\
\hline & $(0.01)^{* *}$ & $(0.00)^{* *}$ & $(0.01)^{* *}$ & $(0.00)^{* *}$ & $(0.00)$ & $(0.00)^{* *}$ \\
\hline
\end{tabular}

Notes: $* *$ and $*$ denote significant at $5 \%$ and $10 \%$ size, respectively. Robust standard errors are in parentheses.

Table 8 provides the partial effects for a selection of variables in the price change equation. ${ }^{28}$ The left panel provides the partial effect of a change in variable $x$ on the probability to decrease, leave unchanged or increase the price, conditional on a price review being implemented. The right panel provides the overall (or marginal) effect of a change in $x$, that is, the total effect accounting for the probability to proceed to a price review in the first stage.

One striking result from these estimates is that the main driver of price changes lies in changes in the price of intermediate inputs. Conditional on a price review being conducted, an increase in input prices magnifies the likelihood of a price change. Even taking into account the fact that not all input price variations do lead firms to proceed to a price review, the final impact on the likelihood of a price increase remains quite significant: when there has been a change in input prices, the probability of a price increase raises by 7.2 percentage points (see column 6). The partial effect estimate associated with the lagged cumulated changes also has a significant impact on both conditional and marginal price changes. This may indicate that firms respond quickly to a shock on intermediate input prices when the shock is large, but delay their response when it is of a limited magnitude. Moreover, while the magnitude of the impact seems to be slightly larger for price increases than for decreases, the difference does not appear to be statistically significant.

The impact of wage increases on price changes appears quite small. This result, as those regarding the impact of intermediate input price changes, are however in

28. Full parameter estimates are provided in Tables A.2 and A.3. 
accordance with those obtained in Loupias and Sevestre (2013) using a simpler, state-dependent model. As emphasized in Loupias and Sevestre (2013), one possible explanation of the difference between the impact of these two variables is that the share of intermediate input costs in total production of French manufacturing firms is significantly higher (about $70 \%$ in 2005) than that of labor cost (around 20\%, SESSI 2005). Leith and Malley (2007) report the same contrast between intermediate input and labor shares in the U.S. manufacturing industry. Moreover, intermediate input price changes are, on average, of a larger magnitude than those of wages, thus leading to an higher likelihood to induce price adjustments. Indeed, Le Bihan, Montornès, and Heckel (2012) show that the average magnitude of wage changes in the French manufacturing industry was, for the period covered, slightly above $2.2 \%$ while that of changes in intermediate good prices reported in Gautier (2008) were about $4 \%$.

Both current and cumulative changes in production also significantly affect price changes, with the former dominating the latter with regard to magnitudes. Finally, while current changes in the sectoral producer price index have only a small and weakly significant effect (on price rises only), its past cumulative changes significantly affect both marginal and conditional decreases and increases. Overall, the hypothesis that, conditional on a price review, firms' decisions regarding price changes can be represented by an $(S, s)$ rule does not seem rejected. This is consistent with the conclusion by Alvarez, Lippi, and Paciello (2011) that firms face both observation and menu costs.

\subsection{A Counterfactual Exercise: What If Prices were Continuously Reviewed?}

Finally, to give a further sense of the respective role of information and menu cost frictions in price stickiness, we use our model estimates to carry out a counterfactual exercise. Namely, we ask what would be the frequency of price changes if prices were continuously reviewed. We proceed by simulating the model over our data sample, altering the covariates so that in the counterfactual simulation the probability of a price review is sent to (nearly) $100 \%$ (versus around $28 \%$ in our baseline model). Performing such a simulation, and averaging over observations, we find that, in this counterfactual scenario, the probability of price change is $71 \%$ per month, as compared to $21 \%$ in the data (and in the baseline model prediction). So one interpretation of our results in structural terms is that nearly two-thirds of price rigidity would vanish if there was no information friction. Such a number is obtained taking $100 \%-21 \%=79 \%$ as an indicator of the degree of price rigidity in the baseline data-consistent case; and $100 \%-71 \%=29 \%$ as an indicator of the degree of price rigidity in the counterfactual case. Conversely, by design of our model, if prices were completely flexible (i.e., assuming, conditional on a review, that the probability of a price change is equal to unity) the frequency of price changes would be equal to the frequency of price reviews, that is, $28 \%$, up from $21 \%$ in the data. ${ }^{29}$

29. We checked that the same value of $28 \%$ was recovered through counterfactual simulations setting to one the conditional probability of a price change. 
Both numbers confirm the evidence of both price setting and information frictions, but that the friction associated with price reviews has a dominant role in our data.

\section{CONCLUSION}

A number of surveys have shown that firms do not review their prices very often, nor do they change their prices frequently. Following Reis (2006), Woodford (2009) and Alvarez, Lippi and Paciello (2011) have developed theoretical models rationalizing the infrequency of price reviews and its impact on the observed price stickiness. Our paper provides one of the first, to our knowledge, pieces of microeconomic evidence assessing the contribution of infrequent price reviews for explaining infrequent price changes. We have carried out this investigation by specifying and estimating a socalled IOP model where the no-change price observations are explicitly modeled as the result of a two-step process. Firms first decide whether or not they should proceed to a price review. If they do, they decide, in a second step, whether they should change (raise or lower) their prices or not. While the researcher does not witness this sequencing of decisions but just the observed price change, or absence of change, the econometric model featuring a choice of explanatory variables informed by theoretical models, can however successfully disentangle these two processes.

Our estimation results show that, indeed, price reviews are infrequent and largely contribute to the observed price rigidity. These price reviews mainly obey a timedependent schedule but they can also be triggered by large and persistent shocks on input prices, production, and the producer price index. These results are in accordance with both the empirical evidence provided in several surveys such as the ones presented in Fabiani et al. (2006) and with the predictions of the models proposed by Woodford (2009) and Alvarez, Lippi, and Paciello (2011). When gathering and analyzing the information required for reviewing their prices, firms face costs that prevent them from doing so on a continuous basis. Regarding the decision to change prices, the results we obtain are similar to those previously obtained, for example, by Loupias and Sevestre (2013) among others: intermediate input prices appear to be an important driver of price changes, possibly with lags.

Overall, this set of results provides evidence on the infrequency of price reviews and the relevance of information costs. As pointed out by, for example, Mankiw and Reis (2002) and Alvarez, Lippi, and Paciello (2016), such a finding is relevant for monetary policy. Providing structural estimates of observation costs, as well as quantitative implications for monetary policy remains a topic for future research.

\section{LITERATURE CITED}

Alvarez, Fernando, Francesco Lippi, and Luigi Paciello. (2011) "Optimal Price Setting with Observation and Menu Costs.” Quarterly Journal of Economics, 126, 1909-60.

Alvarez, Fernando, Francesco Lippi, and Luigi Paciello. (2016) "Monetary Shocks in Models with Inattentive Producers.” Review of Economic Studies, 83, 421-59. 
Alvarez, Luis I., Pablo Burriel, and Ignacio Hernando. (2005) "Do Decreasing Hazard Functions for Price Changes Make Any Sense?” Working Paper No. 0508, Banco de Espana.

Apel, Mikael, Richard Friberg, and Kerstin Hallsten. (2005) "Microfoundations of Macroeconomic Price Adjustment: Survey Evidence from Swedish Firms." Journal of Money, Credit and Banking, 37, 313-38.

Blinder, Alan S., Elie R. D. Canetti, David E. Lebow, and Jeremy B. Rudd. (1998) Asking About Prices: A New Approach to Understanding Price Stickiness. New York: Russell Sage Foundation.

Brooks, Robert D., Mark N. Harris, and Christopher Spencer. (2012) "Inflated Ordered Outcomes." Economics Letters, 117, 683-86.

Cecchetti, Stephen G. (1986) "The Frequency of Price Adjustment : A Study of the Newsstand Prices of Magazines." Journal of Econometrics, 31, 255-74.

Dhyne, Emmanuel, Catherine Fuss, Hashem Pesaran, and Patrick Sevestre. (2011) "Lumpy Price Adjustments: A Microeconometric Analysis." Journal of Business and Economic Statistics, 29, 529-40.

Dixit, Avinash. (1993) The Art of Smooth Pasting. Chur, Switzerland: Harwood Academic Publishers.

Fabiani, Silvia, Martine Druant, Ignacio Hernando, Claudia Kwapil, Bettina Landau, Claire Loupias, Fernando Martins, Thomas Y. Mathä, Roberto Sabbatini, Harald Stahl, and Ad C. J. Stokman. (2006) "What Firms' Surveys Tell Us about Price-Setting Behavior in the Euro Area." International Journal of Central Banking, 2, 3-48.

Fougère, Denis, Hervé Le Bihan, and Patrick Sevestre. (2007) "Heterogeneity in Consumer Price Stickiness: A Microeconometric Investigation." Journal of Business and Economic Statistics, 25, 247-64.

Gautier, Erwan. (2008) "The Behaviour of Producer Prices: Some Evidence from French PPI Micro-Data." Empirical Economics, 35, 301-32.

Gautier, Erwan, and Hervé Le Bihan. (2018) "Shocks vs Menu Costs: Patterns of Price Rigidity in an Estimated Multi-Sector Menu-Cost Model.” Working paper No. 682, Banque de France.

Golosov, Mikhail, and Robert E. Lucas. (2007) "Menu Costs and Phillips Curves." Journal of Political Economy, 155, 171-99.

Harris, Mark N., and Xueyan Zhao. (2007) "A Zero-Inflated Ordered Probit Model, with an Application to Modelling Tobacco Consumption." Journal of Econometrics, 141, 1073-99.

Klenow, Peter J., and Benjamin A. Malin. (2011) "Microeconomic Evidence on Price-Setting." Handbook of Monetary Economics, 3, p. 231-84. Amsterdam: Elsevier.

Konieczny, Jerzy, and Fabio Rumler. (2006) "Regular Adjustment-Theory and Evidence." ECB Working Paper 669, ECB.

Le Bihan, Hervé, Jérémy Montornès, and Thomas Heckel. (2012) "Sticky Wages: Evidence from Quarterly Microeconomic Data." American Economic Journal: Macroeconomics, 4, $1-32$.

Leith, Campbell, and Jim Malley. (2007) "A Sectoral Analysis of Price-Setting Behavior in US Manufacturing Industries." Review of Economics and Statistics, 89, 335-42.

Loupias, Claire, and Roland Ricart. (2004) "Price Setting in France: New Evidence from Survey Data." ECB Working paper 423.

Loupias, Claire, and Roland Ricart. (2006) "Price Setting in the French Manufacturing Sector: New Evidence from Survey Data." Revue d'Economie Politique, 117, 541-54. 
Loupias, Claire, and Patrick Sevestre. (2013) "Costs, Demand and Producer Price Changes." Review of Economics and Statistics, 95, 315-27.

Mackowiak, Bartosz, and Mirko Wiederholt. (2009) "Optimal Sticky Prices under Rational Inattention." American Economic Review, 99, 769-803.

Maddala, G. S. (1983) Limited Dependent and Qualitative Variables in Econometrics. Cambridge, UK: Cambridge University Press.

Mankiw, Gregory N., and Ricardo Reis. (2002) "Sticky Information versus Sticky Prices: A Proposal to Replace the New Keynesian Phillips Curve." Quarterly Journal of Economics, $117,1295-328$.

Nakamura, Emi, and Jon Steinsson. (2010) "Monetary Non-Neutrality in a Multisector Menu Cost Model." Quarterly Journal of Economics, 125, 961-1013.

Reis, Ricardo. (2006) "Inattentive Producers." Review of Economic Studies, 73, 793-821.

Rivers, Douglas, and Quang H. Vuong. (1988) "Limited Information Estimators and Exogeneity Tests for Simultaneous Probit Models.” Journal of Econometrics, 39, 347-366.

SESSI. (2005) http://www.industrie.gouv.fr/sessi/enquetes/eae/eae.php?an=2005.

Sheshinski, Eytan, and Yoram Weiss. (1977) "Inflation and Costs of Price Adjustment.” Review of Economic Studies, 44, 287-303.

Sims, Christopher A. (1998) "Stickiness." Carnegie-Rochester Conference Series on Public Policy, 49, 317-56.

Sims, Christopher A. (2003) "Implications of Rational Inattention." Journal of Monetary Economics, 50, 665-90.

Vermeulen, Philip, Daniel Dias, Maarten Dossche, Erwan Gautier, Ignacio Hernando, Roberto Sabbatini, and Harald Stahl. (2007) "Price Setting in the Euro Area: Some Stylised Facts from Individual Producer Price Data.” ECB Working Paper 727.

Woodford, Michael. (2009) "Information Constrained State-Dependent Pricing." Journal of Monetary Economics, 56, s100-24.

Wooldridge, Jeffrey. (2005) "Simple Solutions to the Initial Conditions Problem in Dynamic, Nonlinear Panel Data Models with Unobserved Heterogeneity." Journal of Applied Econometrics, 20, 39-54.

Wooldridge, Jeffrey M. (2002) Econometric Analysis of Cross Section and Panel Data. Cambridge, MA: MIT Press.

Zbaracki, Mark J., Mark Ritson, Daniel Levy, Shantanu Dutta, and Mark Bergen. (2004) "Managerial and Customer Costs of Price Adjustment: Direct Evidence from Industrial Market." Review of Economics and Statistics, 86, 514-33. 